\title{
Environmental Policy, Public Opinion and Global Climate Change in Southern Europe: The Case of Andalusia
}

\author{
Eduardo Moyano ${ }^{1}$, Angel Paniagua ${ }^{*}, 2$ and Regina Lafuente ${ }^{1}$ \\ ${ }^{I}$ Instituto de Estudios Sociales Avanzados IESA, Spain \\ ${ }^{2}$ Instituto de Políticas y Bienes Públicos IPP, Consejo Superior de Investigaciones Científicas, Spain, CSIC
}

\begin{abstract}
Absract: This paper analyses the multiple relations existing between public opinion, public policies and global climate change from the perspective of environmental sociology. The framework for this research is the problem of environmental scale in the mitigation and adaptation of environmental problems. The case study was conducted in Andalusia, Spain; a southern European region where the impact of climate change is taking on increasing relevance due to the far-reaching effects that variations in precipitation, temperature change and desertification have had and will have on the area. Environmental policy and politics in relation to global climate change are analysed, as well as citizens' attitudes and the main politics of adaptation on a regional scale. The contribution of this paper is that in these southern areas of Europe, citizens give priority to local and regional policies only in reference to the problems of 'their' climate change like soil erosion, precipitation changes or forest fires, but not in terms of global issues which are more difficult for people to identify such as the destruction of the ozone layer, polar icemelt, deforestation or the emission of greenhouse gases, amongst others.
\end{abstract}

Keywords: Global climate change, public opinion, environmental policy, regional scale, Spain.

\section{INTRODUCTION}

Among the issues that form the research agenda of modern environmental sociology, the analysis of people's attitudes, values and behaviour towards questions related to the global environmental (that is, those that affect the planet as a whole) is at the top of the list [1]. The research challenge in this social science field is twofold: on the one hand, we must determine to what extent actions taken by public actors influence how citizens perceive and assess the importance and seriousness of environmental issues, while on the other, it is essential to analyse to what degree public policy reflects how citizens perceive environmental problems. The varying degree of importance that citizens place on global environmental change, as well as the wide variety of attitudes, assessments and behaviours towards the environment constitute a relevant field of study that has multiple implications in both spatial (territorial) and temporal terms [2]. In such a complex context, it is also necessary to highlight the gap that is often reported in the specialised literature between environmental concern and pro-environment attitudes. This question gives rise to further uncertainties when analysing the influence of public opinion on global environmental policymaking [3].

This diversity of attitudes and social perceptions (either for socio-demographic reasons or due to the way environmental problems are manifested in a given geographic area or sphere) make public actions in environmental policy even more complex and the results of adaptation and mitigation

*Address correspondence to this author at the Instituto de Políticas y Bienes Públicos IPP, Consejo Superior de Investigaciones Científicas, CSIC, Spain; E-mail: angelpa@ieg.csic.es measures uncertain [4-7]. Moreover, it is important to bear in mind that while environmental policies are developed and implemented within the framework of well-defined organisational or institutional structures (ministries of the environment or similar departments of the public administration), their orientations, content and development are ultimately the result of a set of social values, beliefs, norms and expectations that predominate in a given society and at a specific moment in time [8]. More recently, and in the wake of debates on climate change, some studies have highlighted the socially constructed nature of the discourses and political disputes that have emerged around these issues $[9,10]$.

Policies for dealing with the problems of climate change are marked by the uncertainty of their effects and the complexity of decision-making processes. This is due to the enormous diversity in the attitudes and behaviour of the actors involved in the debates on climate change and of the public as a whole [4]. If we accept, in scientific terms, that at least some share of climate change is the result of human activity, the analysis of how citizens behave towards these changes becomes especially relevant for shaping policies or defining strategies that are actually viable. This mutual interaction between the political sphere of action and the sphere of individuals' perceptions, values, attitudes and behaviour makes the analysis of public policy on global environmental change an even more complex task. Indeed, some studies on climate change have highlighted the difficulties involved in encompassing the enormous variety of positions and social attitudes on this issue, as well as the wide range of effects that climate change has on human activity [11]. In addition to the complexity of accounting for public opinion in environmental policymaking, it is necessary to design the proper mechanisms and channels for public participation in these 
procedures. In short, the introduction of community-based environmental policies is a multi-dimensional issue in which opposing social interests may come into play [3].

At recent scientific conferences, such as the one held by the Royal Geographic Society in August 2007, experts have stressed this viewpoint and recommended paying greater attention to the social sphere in which strategies for mitigation and adaptation are developed in different political contexts. This viewpoint has also been taken up by a current in the specialised literature [12] and, to a large degree, has been reflected in the Fourth Assessment Report by the Intergovernmental Panel on Climate Change (IPCC). In their report, the panel clearly underlines the importance of encouraging participation by civil society in the decision-making process on the problem of climate change. This recommendation goes one step further than previous approaches to the issue which were limited solely to pursuing the collaboration of the actors directly involved in developing these policies [13]. In this way, the public as a whole has come to be viewed as an essential factor for articulating appropriate and effective policies for climate change.

This article aims to analyse in greater depth the importance of public opinion towards global environmental problems by determining how citizens assess environmental policies in a region such as Andalusia, which is particularly sensitive to climate change. Andalusia - which enjoys sufficient autonomy to develop its own environmental policies [14] - is an example of the so-called implementation deficit of environmental policy in the southernmost area of the EU [15]. Furthermore, in strictly physical and environmental terms, Andalusia is a relevant area of study for measuring the impact of climate change due to the far-reaching effects that variations in precipitation, temperature change and desertification have had and will have on the region.

\section{THE IMPORTANCE OF THE REGIONAL SCALE}

The relationship between public opinion and political action is a prominent issue in environmental sociology. Several studies have confirmed that the amount of money spent by governments can be explained, among other factors, by the influence exerted by citizens' opinions [16,17]. These studies also point out that this influence is not only a result of citizens' general concern for environmental deterioration, but the importance that they give to specific environmental issues that are particularly sensitive at the local or regional level and which have a strong impact on their behaviour or lifestyles. However, both public opinion and environmental policies vary greatly across countries and even across regions in the same country [18]; albeit this variation is more marked at specific moments, such as now, due to climate change [13]. However, it should also be noted -as one current of thought in environmental sociology emphasises- that citizens tend to adapt their daily life to the environmental limitations imposed upon them, thus alleviating their concerns in this regard [19-22].

One of the most relevant debates in environmental policymaking is the scale at which polices for the adaptation and mitigation of global climate change should be developed. As said above, these policies attempt to resolve problems of a strictly environmental nature, but their content and orientation are conditioned by prior political and institutional schemes as well as by public opinion [23]. One notable current of opinion, not only in academic but also in institutional terms, holds that the regional (or even local) level is the most appropriate scale for shaping environmental policy of a participatory nature. By aggregating regional or sub-regional strategies, those affected can be included in the process and consequently more realistic guidelines for action can be set $[24,25,5]$. In the European Union, for example, the regional scale is considered to be the scale of relevance for defining and implementing environmental policies $[26,27]$ and is the scale that has already been used for this purpose in several countries [28].

Numerous international bodies and environmental organisations have stressed that southern Europe is among the geographic areas that will suffer most from the consequences of climate change, particularly the Mediterranean regions. The report by the UN panel predicts that the most negative effects of global warming will be concentrated in southern Europe, thus leading to much hotter summers and lower rainfall, which will in turn result in lower agricultural and forest production and a large area of water stress [29]. Given this context, Andalusia, which is the most southerly and largest region of southern Europe, will be one of the regions most affected by climate change in the future.

The fact that Spain has been recognised as one of the countries that is most subject and vulnerable to climate change has lead policymakers to include this issue on the political agenda. In political terms, it is now widely accepted that climate change will have a greater impact on Spain than the rest of Europe [30]; an opinion that is corroborated by the principle international environmental associations operating in Spain such as ADENA or Greenpeace. The importance given to climate change is evidenced by the leading political role played by Spain through its commitment to palliate this problem in the European Union.

It is within this context that the National Plan for Adaptation to Climate Change has been developed in Spain [13]. The plan, which is based on a participatory scheme proposes the need to develop policies under a regional or sub-regional scenario that foment adaptive behaviour among citizens with regard to the environment. This approach is based on the idea that different environmental policy styles respond to a combination of domestic interests that have to do with the particular relationship between the society and the environment of each territorial sphere [31]. It also recognises that citizens behave in a given political and institutional scenario (local, regional and national) [32] in which international actors and bodies hold a strong weight [33]. Moreover, several studies point out that many types of social behaviour are conditioned by variables related to the physical and environmental context closest to the individual, thus reinforcing the importance of the regional scope [34].

As a result of the directives contained in the abovementioned plan, the Spanish government has recently set in motion what is known as the Spanish Strategy for Climate 
Change and Clean Energy (EECCEL). This strategic plan includes a series of sectorial actions and grants a key role to regional governments (the governments of the autonomous communities of Spain) so that they may develop their own strategies. It should be noted that in the case of Spain, jurisdiction over the environment has been fully transferred to the regional governments.

The Andalusian Strategy for Climate Change is set within this framework of regional initiatives and contains an articulated set of intersectorial measures including the prevention and control of strictly environmental problems; policies for forest development and fire prevention; biodiversity and the mitigation of and adaptation to the impacts caused by climate change. These strategies underscore the importance of global environmental problems in certain geographic areas such as Andalusia, while recognising the IPCC findings that human activity is increasingly responsible for climate change [35].

\section{METHODOLOGY AND DATA: PUBLIC OPINION AND ENVIRONMENTAL CHANGE}

It is common to define environmental problems not only from a physical standpoint [36, 37], but also in terms of how individuals perceive them and how they behave, or attempt to behave, with regard to such problems [10]. As Herrik and Jamieson [38] report in their work, people's political orientations and value systems are two fundamental elements for the social construction of environmental problems and their possible solution [39]. Nonetheless, it is necessary to determine how environmental policies are related to social concerns in order to move forward in the analysis of the political and institutional response to the uncertainties that arise due to global climate change. In order for the political actions on climate change to be sustainable in the long term, individual attitudes and behaviour must be modified. Indeed, these policies will be unviable if citizens' opinions are not taken into account by means of participatory processes [40]. As the United Nations and its dependent organisations have recently pointed out, the success of strategies and polices aimed at both mitigation and adaptation will largely depend on the public support that they receive. Accordingly, they recommend initiatives to encourage full participation by citizens with a view to increasing public understanding of the strategies for combating the problem of climate change [41].

Although the development of public policies through initiatives to promote participation is considered an important issue [42], this guiding principle remains in the early stages in Spain [43]. Public opinion on the environment is normally analysed through surveys which attempt to measure the attitudes and behaviour of a given population regarding this topic. Public opinion surveys are a useful tool for determining particular aspects of the population (and its evolution) regarding processes of global change, albeit those that have been conducted thus far have been carried out at the national level [44]. Nonetheless, several regional studies have shown that public response to this issue varies considerably across regions within the same country. Hence, it will only be possible to develop and construct the appropriate global environmental policies from bottom up by taking into account these geographic differences [45]. Furthermore, according to data from regional studies, it is possible to (re)articulate scenarios for political action with a greater degree of freedom at the regional level than at the national level [36].

Since 2001, the Regional Government of Andalusia has financed the Ecobarometer of Andalusia (EBA). The EBA is an annual survey conducted by the Institute for Advanced Social Studies of Andalusia (IESA-CSIC) to determine the attitudes and behaviour of Andalusian citizens towards the environment and how they assess the policies developed by their regional government. This is the only example in Spain of an annual environmental survey scheme that makes it possible to construct a system of social indicators for measuring periodical variations in environmental awareness.

The EBA is structured in such a way as to include environmental as well as other issues of public interest, that is, issues on which citizens take a particular stance and which are also relevant to public policy design. The EBA attempts to analyse the different dimensions that comprise environmental awareness, taking into account both emotional and cognitive factors as well as attitude and behaviour. In short, the EBA has as its aim to analyse the most common dimensions of human behaviour with regard to the environment as well as examining how citizens assess public institutions based on environmental policy.

The EBA permits Andalusians' concern for the phenomenon of climate change to be measured in a comparative manner with other environmental problems at the supranational scale. Since the first EBA wave (2001), and on an annual basis, this survey includes a closed list with the same issues that are usually examined in environmental analyses at the global scale. This allows us to analyse how public opinion has evolved with regard to this issue. The environmental issues included are the destruction of the ozone layer, deforestation, the shortage of natural resources, climate change, the extinction of species and population growth.

Each EBA survey is conducted using a representative sample of the population of Andalusia comprising 1500 individuals. It has an error level of $2.8 \%$ and a confidence level of $95 \%$. The survey is structured into 5 blocks: a) the social perception of the importance of environmental problems compared to other problems; b) identification of the problems that are of greatest concern to Andalusians at different territorial levels (local, regional, national and global); c) assessment of actors from society and from the public institutions that are involved in developing and implementing environmental policy; d) analysis of individual and collective attitudes and behaviour of Andalusians towards the environment and e) assessment of the environmental policies developed by the regional government. To prepare the present study, we have used the EBAs from 2001 to 2006 and the initial results from the 2007 EBA, chiefly taking into account questions related to citizens' attitudes on global change and their assessment of public policy. 


\section{PUBLIC OPINION AND GLOBAL CHANGE IN AN- DALUSIA}

In Spain, like in other neighbouring countries in its geographical area, the environment is cause for concern among citizens, albeit to a lesser degree than other social or economic problems. According to the most recent opinion survey conducted by the Centre for Sociological Research (CIS) in July 2007 (no. 2728), only $2.7 \%$ of Spaniards cited environmental problems as being the most important in an openanswer question. This low perception of the relative importance of environment-related problems has remained constant and varied little for over a decade. The EBA, which makes reference to this fact, has also found a similar trend [46], albeit with particular characteristics: public concern is polarized in a regular and constant manner around socioeconomic problems (around seven of every ten citizens state that unemployment and the economy are the problems of greatest concern to them), while concern for the environment remains in an intermediate position and only increases in rank when there is a concrete environmental problem (i.e. drought or an ecological disaster). In any case, from 2001 to 2007 the environment moved from the eighth to the second place among the primary concerns of Andalusians, aggregating percentages that have risen from $8.2 \%$ (EBA-2004) to $38.8 \%$ (EBA$2005)$ of respondents who cited environmental concerns as being among the two most important problems in Andalusia. These interannual differences are due to the existence of "interim environmental crises" at the regional or subregional level such as drought, catastrophic forest fires or the chemical contamination of groundwater, which deepen public concern for the state of the environment during the years in which such events occur. It should be noted, however, that this category of problems also includes questions related to water scarcity (in other opinion surveys such as those conducted by the CIS this type of question is included in a separate category, thus reducing the percentage of concern for the environment).

As regards environmental problems in specific geographic areas, the EBA permits respondents to choose, from a closed list, the two problems that most concern them according to a scale of reference (local, regional or global) ${ }^{1}$. Thus, the list of local-level problems includes noise, dirty streets, the lack of parks and gardens, water quality, solid wastes, traffic or air pollution. At the regional level, the list includes forest fires, water shortages, contamination of beaches and rivers, the elimination of industrial waste and the management of natural spaces. Finally, the list of problems at the global scale comprises the ozone hole, climate change, deforestation, the loss of biodiversity and the high population growth on the planet (Table 1).

Although general concern for the environment remains more or less constant, the most significant changes occur chiefly as a result of the different values respondents assign to certain problems rather than others according to the scale of reference [16]. If we observe the global scale, we find that the problem of the ozone hole was perceived by Andalusians

\footnotetext{
${ }^{1}$ This list was drawn up following previous qualitative studies conducted
} before the first EBA (corresponding to 2001). as being the first most important environmental problem on the planet during the 2001-2006 period. However, this problem was surpassed by climate change which was cited as the most important problem in the EBA-2007. In this latest survey, almost half of Andalusians stated that the problem of climate change was of greatest concern to them at the global level (see Table 1).

The polarization of public opinion in Andalusia around these two global-level problems is coherent with the deep concern shared by all Mediterranean countries for the effects of human activity on the climate [35]. This can be explained by the fact that these countries are located in a geographic area in which the impact of climate change (as reflected in temperature and precipitation changes and desertification) has become manifestly evident [32]. In the EBA of 2002, already $74 \%$ of those surveyed (three out of every four) acknowledged that a climate change was occurring on the planet, while only $15 \%$ refused to accept this fact. Five years later, the EBA-2007 found that $62.8 \%$ of Andalusians (almost two of every three) believes that climate change is already a problem, while $22.1 \%$ perceive it to be a problem for the future. This trend coincides with greater information on processes linked to global change and the role that human activity plays in them as well as the more precise knowledge that citizens have regarding the long cyclical nature of these environmental problems. Highly-educated professionals are the social group that shows greatest concern for climate change at the global level; a group that normally shows a higher level of environmental awareness in public opinion surveys on these issues. Furthermore, the EBA-2007 shows that people who are concerned about climate change are also quite knowledgeable about the specific problems of the phenomenon such as precipitation changes or contamination due to the emission of greenhouse gases (more than half of the Andalusians were able to define the problem and indicate its effects). In general, the EBA-2007 reveals that those who are most concerned about environmental problems and most committed to conserving the environment, are also those who show higher levels of concern and knowledge regarding climate change.

Consequently, among the perceived effects of climate change, Andalusians chiefly cite temperature changes (one of every two respondents mention this effect), changes in precipitation (one of every three) or changes in seasonal climate during the year (one of every five). In contrast, the environmental effects that are not perceived through individual experience, but which respondents gain knowledge about through other sources (i.e. polar icemelt, forest fires or the destruction of the ozone layer) are mentioned much less frequently by Andalusians (less than $5 \%$ of those surveyed).

The EBA data reveal that the citizens of Andalusia are quite knowledgeable about the main effects of climate change, suggesting that there exists a good community base for defining an adequate strategy of adaptation in a region that is especially vulnerable in environmental terms [47]. When comparing the EBA-2001 to the EBA-2007, we observe that public opinion in Andalusia is polarized around the problem of temperature change, which is perceived to be 
Table 1. Public Opinion and Global Environmental Change in Andalusia. The Perception of Global Change.

I am Going to Show You a Card with Some General Environmental Problems, that is, those that Affect the Planet. Please Tell Me which Two Problems You Think are the Most Important

\begin{tabular}{|c|c|c|c|c|c|c|c|c|c|c|c|c|c|c|}
\hline & \multicolumn{2}{|c|}{2001} & \multicolumn{2}{|c|}{2002} & \multicolumn{2}{|c|}{2003} & \multicolumn{2}{|c|}{2004} & \multicolumn{2}{|c|}{2005} & \multicolumn{2}{|c|}{2006} & \multicolumn{2}{|c|}{2007} \\
\hline Population growth & 169 & $13.0 \%$ & 223 & $15.4 \%$ & 195 & $13.9 \%$ & 158 & $12.1 \%$ & 149 & $11.4 \%$ & 165 & $12.7 \%$ & 158 & $12.2 \%$ \\
\hline Climate change & 449 & $34.5 \%$ & 457 & $31.6 \%$ & 415 & $29.6 \%$ & 417 & $31.9 \%$ & 557 & $42.7 \%$ & 560 & $43.0 \%$ & 664 & $49.8 \%$ \\
\hline The extinction of species & 367 & $28.2 \%$ & 407 & $28.1 \%$ & 432 & $30.8 \%$ & 382 & $29.3 \%$ & 279 & $21.4 \%$ & 290 & $22.3 \%$ & 252 & $19.5 \%$ \\
\hline Shortage of natural resources & 217 & $16.7 \%$ & 207 & $14.3 \%$ & 292 & $20.8 \%$ & 383 & $29.3 \%$ & 502 & $38.5 \%$ & 498 & $38.2 \%$ & 390 & $30.2 \%$ \\
\hline Destruction of the ozone layer & 701 & $53.9 \%$ & 813 & $56.2 \%$ & 682 & $48.7 \%$ & 672 & $51.5 \%$ & 575 & $44.0 \%$ & 604 & $46.3 \%$ & 597 & $46.2 \%$ \\
\hline Deforestation & 521 & $40.0 \%$ & 606 & $41.8 \%$ & 613 & $43.7 \%$ & 481 & $36.9 \%$ & 396 & $30.4 \%$ & 364 & $27.9 \%$ & 337 & $26.1 \%$ \\
\hline Others & 3 & $.2 \%$ & 7 & $.5 \%$ & 7 & $.5 \%$ & 15 & $1.1 \%$ & 10 & $.8 \%$ & 11 & $.9 \%$ & 14 & $1.1 \%$ \\
\hline Don't know & 173 & $13.3 \%$ & 85 & $5.8 \%$ & 108 & $7.7 \%$ & 29 & $2.2 \%$ & 52 & $4.0 \%$ & 34 & $2.6 \%$ & 116 & $4.9 \%$ \\
\hline No answer & 2 & $.2 \%$ & 5 & $.3 \%$ & 4 & $.3 \%$ & & & 1 & $.1 \%$ & 2 & $.1 \%$ & 73 & $.2 \%$ \\
\hline Total & 1301 & & 1448 & & 1402 & & 1305 & & 1305 & & 1303 & & 1292 & \\
\hline
\end{tabular}

Source: EBAs, 2001 to 2007. Own elaboration.

the principle effect of climate change, while lower rainfall is not considered to be a direct effect of climate change, but is instead assumed to be a natural consequence of the Mediterranean climate. This conclusion has important implications in a geographic area so closely linked to the tourist sector, thus underscoring the need for an adequate policy of adaptation to the effects of climate change.

Another aspect that is related to those mentioned above, but is of particular relevance to policymaking, is how the environmental situation is assessed according to the scale of reference. In the different EBA surveys, we find that there is a tendency to perceive greater environmental deterioration the larger the geographic scale of reference. For example, in the EBA-2006 the mean assessment (on a scale of 1 to 5, where 1 is very bad and 5 is very good) of the environmental situation was 3.08 at the local level, while at the regional level it was 3.02 and at the global level it fell to 2.16. In any case, it is interesting to note that the perception of the environmental situation at the global level is constructed upon certain local and regional problems, especially with regard to soil erosion or desertification, which is even more pronounced as a result of higher temperatures or lower precipitation. These are, however, problems that are expressed on a well-defined territorial base.

\section{PUBLIC OPINION, ENVIRONMENTAL POLICY AND GLOBAL CHANGE}

One of the difficulties that socio-environmental research encounters when orienting policies for mitigation or adaptation to global environmental problems (such as those related to climate change as well as the loss of biodiversity or desertification), is to link citizens' awareness of the general effects of climate change to the specific problems these effects cause in a given territory [45]. This difficulty lies in the fact that it is not an easy task to translate the seriousness of global environmental problems to the conscience of inhabitants in a given area, as this involves not only integrating these problems into the mechanisms of individual percep- tion, but in the concrete socioeconomic perspectives and the predominant value system of each territory. This can also have far-reaching repercussions on the social assessment of public policy and the institutions that develop them. How they are assessed will depend on the scale at which each institution develops its sustainable actions and how citizens perceive the need to implement policies for adaptation to or mitigation of the problems caused by global change.

However, when faced with the dilemmas of placing their trust in governments or even civil society to solve environmental problems (be they global, local or regional), the citizens of Andalusia are clearly inclined towards the role of the state in this matter. In the EBA-2001, already around $80 \%$ of the respondents stated that they agreed with the option that "it is the government's responsibility to solve environmental problems through its laws"; a percentage which in spite of having declined in the most recent EBA surveys, continues to remain at around $56 \%$. Cramer's V statistic, which has been used in the different EBA surveys to summarise the assessment of trust in public institutions, reveals that the value of this index is higher when the respondent refers to global problems. Thus it is possible to say that the variable related to global problems is also related to political attitude (trust in institutions, trust in the government and trust in the public administration).

When assigning responsibility to the institutions in charge of implementing environmental policy, public opinion is shown to be influenced by the level or sphere of action. For example, environmental policies that have been implemented by regional institutions are only considered relevant at that same level of action since citizens consider that these types of measures do not make a significant contribution to solving the problems of climate change at the global level (e.g. the EBAs of 2001 and 2006, where all the correlations are significant between the environmental policies implemented by the Regional Government of Andalusia and the environmental problems affecting the region). It is widely believed that environmental policies developed at the 
Table 2. Public Opinion and Regional Public Policies

\begin{tabular}{|c|c|c|c|c|c|c|c|c|c|c|c|c|c|c|}
\hline \multicolumn{15}{|c|}{$\begin{array}{c}\text { To the Best of Your Knowledge, how would You Assess the Measures Taken by the Regional Government of Andalusia with Regard to the } \\
\text { Following Topics that I Am Going to List to You. Please Indicate if You Think they are Very Negative (1), Negative (2), Normal (3), Positive (4) } \\
\text { or Very Positive (5) }\end{array}$} \\
\hline & \multicolumn{2}{|c|}{2001} & \multicolumn{2}{|c|}{2002} & \multicolumn{2}{|c|}{2003} & \multicolumn{2}{|c|}{2004} & \multicolumn{2}{|c|}{2005} & \multicolumn{2}{|c|}{2006} & \multicolumn{2}{|c|}{2007} \\
\hline & Mean & SD & Mean & SD & Mean & SD & Mean & SD & Mean & SD & Mean & SD & Mean & SD \\
\hline $\begin{array}{l}\text { Assessment of the Regional Government } \\
\text { of Andalusia regarding the environment }\end{array}$ & & & 3.35 & .821 & 3.39 & .777 & 3.24 & .839 & 3.180 & .843 & 3.23 & .80 & 3.31 & .815 \\
\hline Protection of natural areas & 3.62 & .804 & 3.66 & .768 & 3.54 & .812 & 3.59 & .836 & 3.464 & .865 & 3.43 & .83 & 3.37 & .866 \\
\hline Combating forest fires & 3.75 & .764 & 3.70 & .787 & 3.61 & .799 & 3.65 & .797 & 3.385 & .944 & 3.42 & .83 & 3.42 & .880 \\
\hline Conservation of animal and plant species & 3.60 & .832 & 3.58 & .851 & 3.50 & .839 & 3.50 & .844 & 3.443 & .891 & 3.39 & .88 & 3.45 & .870 \\
\hline Control of air pollution & 3.11 & .968 & 3.08 & .947 & 3.06 & .920 & 3.08 & .931 & 3.008 & .961 & 3.03 & .90 & 3.04 & .938 \\
\hline $\begin{array}{l}\text { Management of waters and contaminating } \\
\text { spills }\end{array}$ & 3.12 & 1.017 & 3.04 & 1.021 & 3.02 & .956 & 3.06 & .938 & 3.063 & .958 & 3.03 & .91 & 3.08 & .962 \\
\hline Industrial waste management & 3.02 & 1.031 & 2.96 & 1.035 & 2.94 & .956 & 3.11 & .959 & 3.150 & .927 & 2.93 & .96 & 3.05 & .932 \\
\hline Promotion of volunteer work & 3.32 & .982 & 3.35 & .970 & 3.33 & .972 & 3.32 & .908 & 3.323 & .893 & 3.33 & .89 & 3.33 & .873 \\
\hline Urban waste management & 3.51 & .918 & 3.39 & .971 & 3.50 & .921 & 3.44 & .878 & 3.388 & .882 & 3.14 & .92 & 3.33 & .888 \\
\hline $\begin{array}{l}\text { Energy savings and fomenting new sources } \\
\text { of energy }\end{array}$ & 3.31 & .968 & 3.27 & .950 & 3.27 & .908 & 3.29 & .908 & 3.323 & .882 & 3.28 & .85 & & \\
\hline Combating climate change & & & & & & & & & & & & & 3.11 & .895 \\
\hline
\end{tabular}

national or international (European) level and the institutions that implement them are responsible for palliating environmental problems at the global level. This explains why citizens directly associate the scale of environmental problems with the territorial level of the policies and institutions in charge of solving or mitigating them. If we take the EBAs as a reference, the correlations analysis reveals the existence of a clear positive association between the scale of the environmental problems and the degree of responsibility that citizens attribute to the institutions in charge of implementing the policies in each territorial sphere (global-European, national, regional or local). For example, citizens in Andalusia assign greater responsibility to city halls for solving local environmental problems (noise, dirty streets, traffic) and to the regional government for specific issues that have to do with the environment at the regional level (forest fires, water, contamination, etc.), but not for issues related to climate change.

The general assessment made by Andalusians regarding regional environmental policy remains at very stable levels across the EBA surveys. This is also true with regard to the assessment of sectorial policies and policies to combat climate change (see Table 2). The consistency of the mean values in both temporal and sectorial terms is one of the main characteristics of public opinion and regional environmental policy in Andalusia. This demonstrates that when Andalusians assess policymaking, they do not distinguish between regional environmental policies in general, sectorial policies and policies aimed at combating climate change, but they perceive of and assess the problem as a whole, without considering whether certain policies contribute more than others to solving environmental problems. These results suggest a certain amount of independence between the evolution of Andalusians' general concern for the global environment (which is gradually increasing) and their assessment of regional policy. It also suggests that Andalusians still do not clearly understand that in order to combat climate change the process must begin with a series of sectorial actions at the regional level. In the Andalusians' opinion, the solution to global environmental problems should be sought at a level other than the regional one. Consequently, when assessing global climate change, Andalusians do not relate it to regional actions, but view it from a vertical perspective (updown), coinciding with the great amount of trust they place on public authorities as preferential actors of environmental regulation (Table 3 ).

With a view to corroborating these viewpoints, we have analysed the assessments made by Andalusians regarding sectorial-type regional policies using data from the 2006 and 2007 EBA (where almost half the population of Andalusia is found to be concerned about the problem of global climate change as explained above). If we compare those who express their concern for climate change and those who state they are concerned about other environmental problems, no clear difference is found between the two groups in terms of their assessment of the regional government's environmental policy on the whole. In the case of specific actions or environmental policies, these groups do not reveal significant differences in the two years studied. This reaffirms the viewpoint expressed above regarding the consistency of the assessments of regional government environmental policy (around intermediate values). However, the fact that the respondent expresses deep concern for climate change or is instead more preoccupied by other problems is not a dis- 
Table 3. Trust in the Different Decision-Making Levels in Relation to Global Environmental Problems. Valuation of Regional Population of Environmental Policies. Correlations Between Valuation Regional Environmental Policies and Other Scales

\begin{tabular}{|c|c|c|c|}
\hline Regional Government of Andalusia & European Union & Government of Spain & City Halls \\
\hline \hline EBA 2001 & 0.629 & 0.754 & 0.780 \\
\hline 2002 & 0.539 & 0.694 & 0.717 \\
\hline 2003 & 0.664 & 0.791 & 0.766 \\
\hline 2004 & 0.567 & 0.749 & 0.822 \\
\hline 2005 & 0.688 & 0.864 & 0.826 \\
\hline 2006 & 0.626 & 0.853 & 0.824 \\
\hline 2007 & 0.589 & 0.806 & 0.809 \\
\hline
\end{tabular}

criminating element in this assessment. We can argue, then, that global environmental policy is considered by Andalusians to be a 'policy of policies' and as stated above, the regional level is perceived as being subsidiary when fomenting sustainable development at the global level.

This line of reasoning underscores the notable and significant positive association between different geographic scales in environmental policymaking among those who hold the opinion that climate change is the most important problem and among those who do not (see Tables 3 and $\mathbf{4}$ ). But it also reveals that those who positively assess the regional government's actions to combat global climate change, also strongly back measures developed by other institutions at either the national or the European Union level. Hence, it is possible to state that the public support of actions aimed at mitigation form part of the positive assessment of environmental policies, not only at the regional level but at other institutional levels as well (Tables $\mathbf{3}$ and $\mathbf{4}$ ).

\section{CONCLUSIONS}

The attitudes and behaviour towards climate change are notably complex [48]. This paper attempts to make a contribution to a particular aspect that has gained increasing importance in the literature, namely the interaction between public opinion and policies for mitigating global environmental change under sub-national (regional) scenarios.

The analysis of policies on global change is interesting in the case of southern Europe as policymaking in this area has been traditionally characterised in the specialised literature as being subsidiary to the environmental interests of northern Europe [49]. Environmental problems due to climate change have become a primary concern of Andalusians coinciding with the development of political strategies and public actions to mitigate them. Nonetheless, the ranking of climate change as the primary concern of Andalusians is linked to their concern for concrete problems in the region such as rising temperatures, precipitation changes, the advance of desertification or the already visible soil erosion.

Perhaps one of the most interesting results of the analysis using the EBA data is the fact that it raises the issue of the importance of sub-national policies for developing sustainable strategies at the global level. Although environmental sociology underlines the importance of implementing geographically localised policies [50], the EBA of Andalusia does not confirm this hypothesis. In fact, the citizens of Andalusia are able to make a clear distinction between which institutions are responsible for solving what problems according to their geographical scale (local, regional, national or European) and do not perceive local or regional policies as being key to combating global change. But there is also a notable positive association between the assessment of regional government policy in Andalusia and the evaluation of national and European policies (Table 3). This reveals the predominance of a vertical (up-down) perspective in Andalusian public opinion regarding strategies to combat global change and the fact that regional institutions are not held responsible for mitigating global climate change, but instead the European Union or the government of Spain. Furthermore, this takes place under a framework in which public authorities are awarded a prominent role in the process, while civil society merely plays a subsidiary role.

It has been suggested in the specialised literature [2] that environmental problems due to climate change may modify the classic schemes that have thus far shaped polices for sustainable development in that they underscore the importance of sub-national policies. However, in the case of the southernmost area of Europe, and more specifically Andalusia, citizens give priority to local and regional policies only in reference to the problems of 'their' climate change (soil erosion, precipitation changes, forest fires, etc.), but not in

Table 4. Valuation Between Policies to Combat Climate Change by the Regional Government of Andalusia and Trust in the Environmental Policies of Different Institutions in 2007 (Bivariate Correlations)

\begin{tabular}{|c|c|c|c|c|}
\hline & European Union & Government of Spain & Regional Government of Andalusia & City Halls \\
\hline \hline Combat climate change & 0.222 & 0.244 & 0.247 & 0.220 \\
\hline
\end{tabular}


terms of global issues which are more difficult for the population to identify (destruction of the ozone layer, polar icemelt, deforestation, emission of greenhouse gases, etc.).

This points to the specialisation of environmental policies in regions which, due to their geographical location, are critical about the process of global change especially when identifying the most extreme effects of this phenomenon. However, this trend clearly involves the regionalisation of environmental policy in the most southerly areas of Europe, in contrast to the dominant trend to implement environmental policies under the European framework.

\section{ACKNOWLEDGEMENTS}

We want to thank the referees for your comments and suggestions, which have improved the definitive version of our paper. The translation to English version has been made by Martha Gaustaad.

\section{REFERENCES}

[1] Seacrest S, Kuzelka R, Leonard R. Global climate change and public perception: the challenge of translation. J Am Water Resour As 2000; 36 (2): 253-263.

[2] Cohen S, Demeritt D, Robinson J, Rothman D. Climate change and sustainable development: towards dialogue. Glob Environ Change 1998; 8 (4): 341-371.

[3] Wilson GA, Bryant RL. Environmental Management. New directions for the twenty-first century. UCL Press: London, 1997.

[4] Dessai S, O’Brien K, Hulme M. Editorial: on uncertainty and climate change. Glob Environ Change 2007; 17:1-3.

[5] Paniagua A, Moyano E. Medioambiente, desarrollo sostenible y escalas de sustentabilidad. Rev Esp Invest Sociol 1998; jul-ago: 151-178.

[6] Tabara D. Spain: words that succeed and climate policies that fail. Clim Policy 2003; 3-1: 19-30.

[7] Yabar A. Mecanismos de consulta, participación y cooperación para una estrategia española de cambio climático. $\mathrm{M}+\mathrm{A}$, revista electrónica de medioambiente. 2006; 2.

[8] O'Riordan T, Jordan A. Social institutions and climate change. O'Riordan T, Jager J, Eds. Politics of climate change. An European perspective. Routledge: London, 65-105: 1996

[9] Pettenger ME. The social construction of climate change. Ashgate: London, 2007.

[10] Sunderlin WD. Global environmental change, sociology, and paradigm isolation. Glob Environ Change 1995; 5 (3): 211-220.

[11] O'Riordan T, Jordan A. Institutions, climate change and cultural theory: towards a common analytical framework. Glob Environ Change 1999; 9 (2): 81-93.

[12] Tjernston E, Tietenberg T. Do differences in attitudes explain differences in national climate change policies? Ecol Econ 2008; 65, 2: 315-324.

[13] Ministry of Environment. Plan Nacional de Adaptación al Cambio Climático, 2007. [about 59 screens] Available from: www.mma.es/ portal/secciones/cambio_climatico/areas tematicas.

[14] Borzel TA. Environmental leaders and laggards in Europe. Why there is (not) a 'Southern Problem', Ashgate, London, 2003.

[15] Liefferink J.D, Lowe PD, Mol APJ Eds. European integration and environmental policy. Belhaven Press: London, 1993.

[16] Dunlap RE. Public opinion and environmental policy. Lester JP, ed. Environmental Politics and Policy. Theories and Evidence. Duke Univ. Press, Durham: 64-114. 1995.

[17] Beatty KM. Public opinion data for environmental decision making: the case of Colorado Springs. Environ Impact Assess Rev 1991; 11: 29-51.

[18] Milfont TL, Duckitt J, Cameron LD. A cross-cultural study of environmental motive concerns and their implications for proenvironmental behaviour. Environ Behav 2006; 38 (6): 745-767.

[19] Blake DE. Contextual effects on environmental attitudes and behaviour. Environ Behav 2001; 33 (5): 708-725.
[20] Gooch GD. Environmental beliefs and attitudes in Sweden and the Baltic states. Environ Behav 1995; 27 (4): 513-539.

[21] Scott D, Willits FK. Environmental attitudes and behaviour. A Pennsylvania survey. Environ Behav 1994; 26 (2): 239-260.

[22] Carrus G, Bonauto M, Bonnes M. Environmental concern, regional identity, and support for protected areas in Italy. Environ Behav 2005; 37 (2): 237-257.

[23] Hannigan JA. Environmental sociology. Taylor and Francis, London, 2007.

[24] Vorkin M, Riese H. Environmental concern in a local context. Environ Behav 2001; 33 (2): 249-263.

[25] Ignatow G. Cultural models of nature and society. Reconsidering environmental attitudes and concern. Environ Behav 2006; 38 (4): 441-461.

[26] Bodiguel M Buller H. Environmental policy and the regions in France. Reg Polit Policy 1994; 4: 92-109.

[27] Buller H. Local actors, national stage, European theatre: Europeanization, nationalization and localization in European community environmental policy, 1995; Burdeos, France.

[28] Buller H, Lowe Ph, Flynn A. National responses to the Europeanisation of environmental policy: a selective review of comparative research. Liefferink JD, Lowe Ph, Mol PJ, Eds. European integration and environmental policy, Belhaven Press London, 1993.

[29] Karas J. El cambio climático en la región mediterránea. Greenpeace: Barcelona, 1997.

[30] Narbona C. El cambio climático en España es mayor que en el resto de Europa, 2005. Actualidad Ciencia y Tecnología. [about 2 pages] Available from: http//actualidad.terra.es/artículo/html/ av2146760.

[31] Kasapoglu M.A, Ecevit MC. Attitudes and behaviour toward the environment. The case of Lake Burdur in Turkey. Environ Behav 2002; 34 (3): 363-377.

[32] Niemeyer S, Petts J, Hobson K. Rapid climate change and society: assessing responses and thresholds. Risk Anal 2005; 25 (6): 14431456.

[33] Fisher DR. Global and domestic actors within the global climate change regime: toward a theory of the global environmental system. Int J Sociol Soc Policy 2003; 23 (10): 5-30.

[34] Slimak MW, Dietz T. Personal values, beliefs, and ecological risk perception. Risk Anal 2006; 26 (6): 1689-1705.

[35] Regional Goverment of Andalusia. Estrategia andaluza ante el cambio climático. Junta de Andalucía: Sevilla, 2007.

[36] Jones S. Social constructionism and the environment: through the quagmire. Glob Environ Change 2002; 12: 247-251.

[37] Jones RE, Dunlap RE. The social bases of environmental concern: have they changed over time? Rural Sociol 1992; 57 (1): 28-47.

[38] Herrick Ch, Jamieson D. The social construction of acid rain. Some implications for science/policy assessment. Glob Environ Change 1995; 5 (2): 105-112.

[39] Penning-Rowsell E, Johnson C, Tunstall S. 'Signals' from precrisis discourse: Lessons from UK flooding for global environmental policy change? Glob Environ Change 2006; 16: 323-339.

[40] Lorenzoni I, Nicholson-Cole S, Whitmarsh L. Barries perceived to engaging with climate change among the UK public and their policy implications. Glob Environ Change, doi 10.1016/j.gloenvcha. 2007.01.004.

[41] UNFCCC. Convención marco de la Naciones Unidas sobre el Cambio Climático. Secretaria del Cambio Climático: Bonn, 2004.

[42] Lorenzoni I, Pidgeon N. Public views on climate change: European and USA perspectivas. Clim Change 2006; 77 (1-2): 73-95.

[43] Sunyer C, Hueso K. National Report. SOBIO. Mobilising the European social research potential in support of biodiversity and ecosystem management. Terra: Spain, 2004.

[44] Brechin SR. Comparative public opinion and knowledge on global climatic change and the Kyoto Protocol: the US versus the world? Int J Sociol Soc Policy 2003; 23 (10): 106-134.

[45] Harrington LMB. Attitudes toward climate change: major emitters in southwestern Kansas. Clim Res 2001; 16: 113-122.

[46] Moyano E, Jiménez M. Los andaluces y el medio ambiente. Junta de Andalucía: Sevilla, 2005.

[47] Handmer JW, Dovers S, Downing TE. Societal vulnerability to climate change and variability. Mitigation and Adaptation Strategies for Glob Change 1999; 4: 267-281. 
[48] O'Connor RE, Bord RJ, Fisher A. Risk perceptions, general environmental beliefs, and willingness to address climate change. Risk Anal 1999; 19 (3): 461-471.

[49] Pridham G, Konstadakopulos D. Sustainable development in Mediterranean Europe? Interaction between European, national and sub-national levels. Baker S, Kousis M, Richardson D, Young S,
Eds. The politics of sustainable development. Theory, policy and practice within the European Union. Routledge, London: 127-151, 1997.

[50] Barr S, Gilg A, Ford N. Environmentalism in Britain today. Who are environmentalists? Town Ctry Plann 2003; 185-186.

(C) Moyano et al.; Licensee Bentham Open.

This is an open access article distributed under the terms of the Creative Commons Attribution License (http://creativecommons.org/licenses/by/2.5/), which permits unrestrictive use, distribution, and reproduction in any medium, provided the original work is properly cited. 